\title{
An improved process for the synthesis of VPI-5 molecular sieve
}

\author{
N VENKATATHRI \\ Catalysis Division, National Chemical Laboratory, Pune 411 008, India
}

MS received 2 September 2002; revised 2 January 2003

\begin{abstract}
VPI-5 was synthesized with lesser time duration. The synthesized sample was characterized by XRD, SEM, FT-IR, TG/DTA, ${ }^{27} \mathrm{Al}$ and ${ }^{31} \mathrm{P}$ MASNMR techniques, which shows that the synthesized sample was highly crystalline. Carbon and nitrogen analyses reveal that the sample contains no template molecules, however, TG/DTA analysis shows the presence of physisorbed template molecules. MASNMR results show the presence of three different types of aluminium and phosphorous. Two of them were present as in tetrahedral and the remaining one is present in octahedral environment.
\end{abstract}

Keywords. VPI-5; synthesis; XRD; SEM; TG/DTA; FT-IR; MASNMR.

\section{Introduction}

Since the first discovery of zeolite, numerous natural and synthetic zeolites (Breck 1973; Barrer 1982), silica polymorphs, aluminophosphate based molecular sieves (Wilson et al 1982; Lok et al 1984), and microporous compounds built from $\mathrm{MO}_{4}$ tetrahedra (where $\mathrm{M}$ is neither aluminium nor silicon, e.g. gallophosphate microporous crystal (Parise 1985; Yang et al 1987)) have been brought to light. These materials are prepared hydrothermally and some of them possess new framework structures. VPI-5 (Davis et al 1988) is an extra-large ring aluminophosphate microporous material consisting of 18 tetrahedral (18T) atoms. Although there are several studies on its characterization (Davis et al 1989; Rocha et al 1992; Engelhardt and Veeman 1993; Ernst et al 1993; He and Klinowski 1994; Rocha et al 1996), only few studies (Schmidt et al 1992) were on its synthesis. Here for the first time we are reporting the synthesis of VPI-5 at lesser duration i.e. at $2 \mathrm{~h}$ compared to the former at $4 \mathrm{~h}$ ( $\mathrm{He}$ and Klinowski 1994). Further the sample was characterized by XRD, SEM, TG/DTA, FT$\mathrm{IR},{ }^{27} \mathrm{Al}$ and ${ }^{31} \mathrm{P}$ MASNMR techniques.

\section{Experimental}

VPI-5 was synthesized as follows: $3.58 \mathrm{~g}$ of pseudoboehmite ( $74.2 \% \mathrm{Al}_{2} \mathrm{O}_{3}$, Vista Chemicals, USA) was mixed with $10 \mathrm{ml}$ of distilled water. $5.75 \mathrm{~g}$ of ortho phosphoric acid $(85 \%$, s.d. fine, India) was added dropwise to the above mixture. The resulting thick white paste was aged for overnight at room temperature. $2.969 \mathrm{~g}$ of di- $n$-propyl amine (98\%, Aldrich, India) along with $10 \mathrm{ml}$ of distilled water was added dropwise to the white paste. The mixture was stirred well. The resulting active gel was charged into a teflon lined steel autoclave. Crystallization was carried out for $2 \mathrm{~h}$ at $142^{\circ} \mathrm{C}$. The autoclave was quenched in cold water and the product removed, washed several times with distilled water and dried at ambient temperature. The resulting solid material was subjected to various physicochemical characterization.

The sample synthesized during the course of the work was analysed for qualitative identification by X-ray powder diffraction (Rigaku, Model D/MAX III VC, Japan; $\mathrm{Ni}$ filtered $\mathrm{Cu}-\mathrm{K} \alpha$ radiation, $\lambda=1.5404 \AA$; graphite crystal monochromater; computer controlled automated diffractometer). The morphologies of the aluminophosphate synthesized was investigated using a scanning electron microscope (JEOL, JSM 5200). The framework region $\left(400-1300 \mathrm{~cm}^{-1}\right)$ of the synthesized aluminophosphates was analysed using a Nicolet 60SXB FT-IR instrument in the diffuse reflectance mode using a $1: 300$ ratio of the sample to $\mathrm{KBr}$ mixture. Simultaneous TG/DTA analyses of the crystalline phases were performed on an automatic derivatograph (Setaram TG-DTA92). The thermograms were recorded in flow of air with heating rate $10 \mathrm{~K} / \mathrm{min}$. MASNMR spectra were recorded in the solid state with a Bruker DRX 500 spectrometer operating at a field of 7 Tesla. ${ }^{27} \mathrm{Al}$ spectra were recorded at a frequency of $78.2 \mathrm{KHz}$, with a pulse length of $2 \mu \mathrm{s}$ and a spinning speed of $3-5 \mathrm{KHz} .{ }^{31} \mathrm{P}$ spectra were recorded at a frequency of $202.45 \mathrm{MHz}$ with pulse length $1.5 \mu$ s and the recycle delay is $4 \mathrm{~s}$.

\section{Results and discussion}

The X-ray powder diffraction (XRD) pattern of the VPI-5 so synthesized is shown in figure 1. The XRD pattern of VPI-5 is similar to the samples prepared using other methods, although peak intensities differ. The synthesis of VPI-5 was facilitated in lesser duration compared to former reported one (He and Klinowski 1994). This may 
be due to the following reasons. In our case, the aluminophosphate paste was aged for overnight. Aging may cause the formation of aluminophosphate layers which on addition of template and water becomes well dispersed particles and are ready for crystallization. So within $2 \mathrm{~h}$ of crystallization the process was completed. Scanning electron microscopy (SEM) shows that the VPI-5 exists as layers and also indicates that the product is pure. The FT-IR spectrum shows (figure 2) three bands at 1272$955,801-625$ and $478.3 \mathrm{~cm}^{-1}$, which are characteristic of aluminophosphate molecular sieves. The asymmetric stretching vibrations of the P-O-Al unit occur at $1267 \cdot 1$, 1170.5 and $1072.3 \mathrm{~cm}^{-1}$ and symmetric stretching vibrations of $\mathrm{P}-\mathrm{O}-\mathrm{Al}$ occur at 744.5 and $600 \mathrm{~cm}^{-1}$. The band at $478.3 \mathrm{~cm}^{-1}$ arises from the vibration of the $\mathrm{P}-\mathrm{O}-\mathrm{Al}$ bending vibrations of the aluminophosphate framework.

The VPI-5 sample was subjected to thermal analysis on a differential thermal analysis (DTA) instrument under the flow of air at a rate of $10^{\circ} \mathrm{C} \mathrm{min}^{-1}$ (figure 3). Thermogravimetric analysis indicated losses of $26 \cdot 14 \% \mathrm{~m} / \mathrm{m}$ from 25 to $731^{\circ} \mathrm{C}$. This mass loss corresponds to the amount of organic molecules and water absorbed by VPI5. The exothermic peak at $251^{\circ} \mathrm{C}$ is caused by a phase change. Carbon and nitrogen analyses show the absence of any organic material in the solid. It is known from the earlier report that the VPI-5 molecular sieve contains

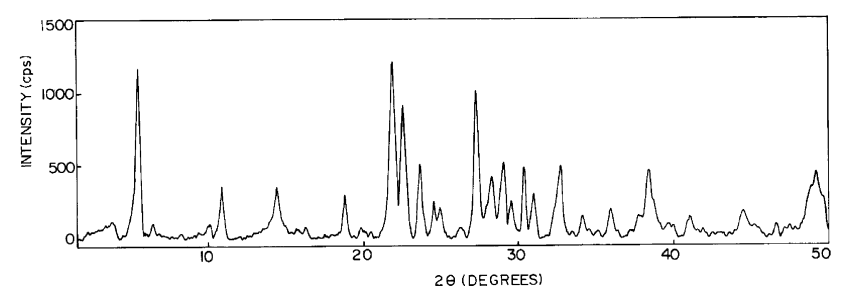

Figure 1. X-ray powder diffraction pattern of VPI-5.

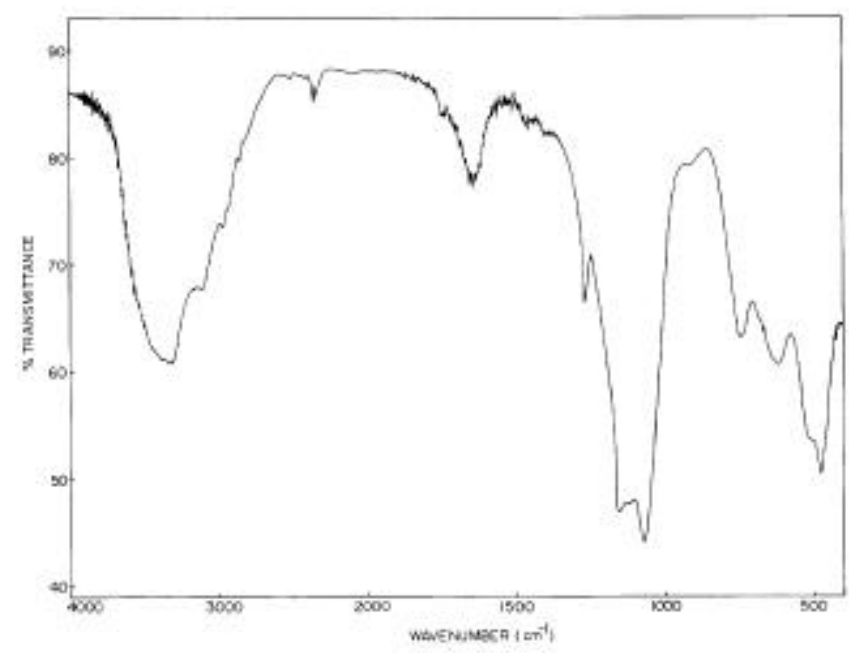

Figure 2. FT-IR spectra of VPI-5 in the framework region. template $(0.4$ (molar ratio) di- $n$-propyl amine) (Robson and Lillerud 2001). However, another study (Davis et al 1989), from chemical analysis and TGA/DSC techniques indicate that there is no template molecule (tetrabutyl ammonium hydroxide) present in VPI-5 molecular sieve but it contains some water. Practically there is no much difference between di- $n$-propyl amine and tetrabutyl ammonium hydroxide in size. Our carbon, nitrogen and FT-IR analyses on same molecular sieve show the absence of any template (di- $n$-propyl amine) molecules. However, the TG/DTA analysis shows the presence of small amount of template molecules $(\sim 5 \%)$, calculated from the higher temperature elimination $\left(200-731^{\circ} \mathrm{C}\right)$. The reason for two different reports on same molecular sieve is not known. This may be due to the earlier crystallization of the molecular sieve. Techniques such as carbon and nitrogen analyses and FT-IR techniques are not precise enough to identify the trace amount of template molecules present in the sample, is clear.

The crystal structure of hydrated VPI-5 (space group $P 6_{3}$ ) (McCusker and Baerlocher 1991) reveals the presence of three crystallographically inequivalent $\mathrm{Al}$ and $\mathrm{P}$ sites in the aluminophosphate framework, two of them located at the connection of six- and four-membered rings [4/6 sites $\mathrm{Al}(2), \mathrm{P}(2)$ and $\mathrm{Al}(3), \mathrm{P}(3)]$ and the third in fused four-membered rings [4/4 site $\mathrm{Al}(1), \mathrm{P}(1)]$. While $\mathrm{Al}(2)$ and $\mathrm{Al}(3)$ are tetrahedrally coordinated to four framework oxygens, $\mathrm{Al}(1)$ is octahedrally coordinated to four framework oxygens and to two water molecules. In agreement with this structure, the ${ }^{31} \mathrm{P}$ MAS (magic angle spinning NMR spectrum) of hydrated VPI-5 consists of three resonances of equal intensity at $\delta-24.8$ $\left(\mathrm{P}^{\mathrm{A}}\right),-28.6\left(\mathrm{P}^{\mathrm{B}}\right)$ and $-34.2\left(\mathrm{P}^{\mathrm{C}}\right)$ (Grobet et al 1989) and three resonance could also be resolved in the ${ }^{27} \mathrm{Al}$ MASNMR, isotropic chemical shifts of $\delta 36\left(\mathrm{Al}^{\mathrm{A}}\right), 3$ $\left(\mathrm{Al}^{\mathrm{B}}\right)$ and $-20\left(\mathrm{Al}^{\mathrm{C}}\right)$ (Grobet et al 1991) (figure 4). van Eck and Veeman (1993) have shown that chemical shift

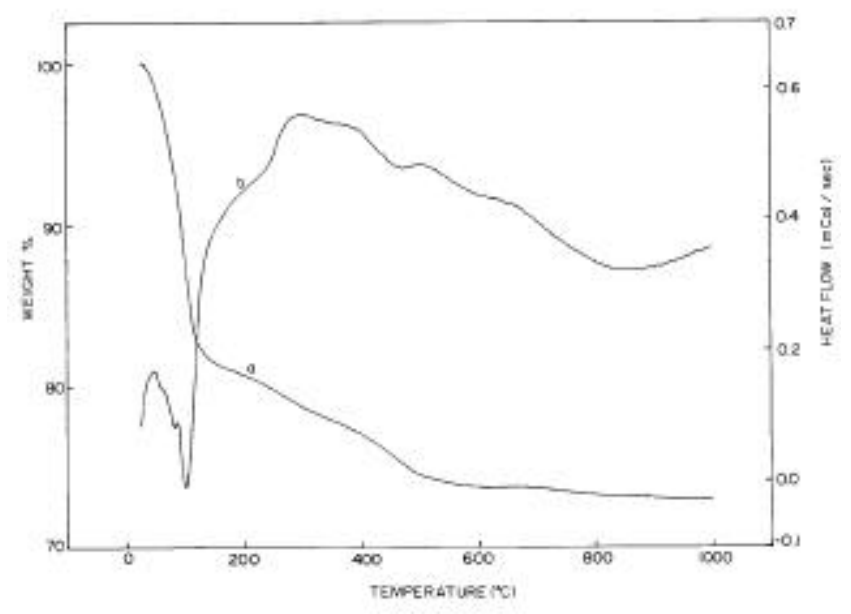

Figure 3. TGA (a) and DTA(b) curves of VPI-5. 


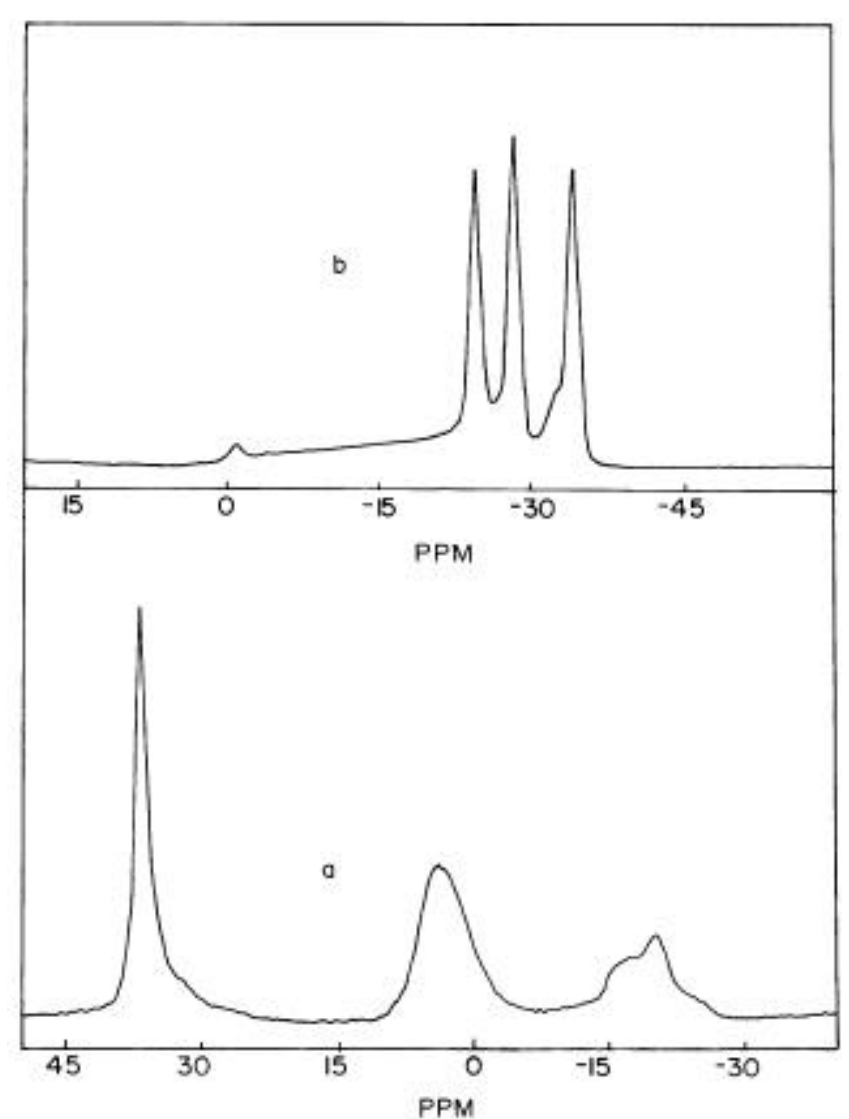

Figure 4. ${ }^{27} \mathrm{Al}$ MASNMR (a) and ${ }^{31} \mathrm{P}$ MASNMR (b) of assynthesized VPI-5.

line $\mathrm{Al}^{\mathrm{C}}$ can unambiguously be attributed to the octahedral $\mathrm{Al}(1)$ site and the $\mathrm{P}^{31}$ peak $\mathrm{P}^{\mathrm{C}}$ must be assigned to $P(1)$. The two peaks $\mathrm{Al}^{\mathrm{A}}$ and $\mathrm{Al}^{\mathrm{B}}$ have been assigned to $\mathrm{Al}(2)$ and $\mathrm{Al}(3)$, respectively, by Grobet et al and the interpretation is correct, an assignment of the ${ }^{31} \mathrm{P}$ peak $\mathrm{P}^{\mathrm{A}}$ to site $\mathrm{P}(2)$ and $\mathrm{P}^{\mathrm{B}}$ to site $\mathrm{P}(3)$ would follow from the correlation spectrum. A shoulder peak at $-33 \mathrm{ppm}$ for ${ }^{31} \mathrm{P}$ MASNMR is due to phosphorous pentoxide impurities and small peak at $-17 \mathrm{ppm}$ in ${ }^{27} \mathrm{Al}$ MASNMR is due to side bands of the tetrahedrally coordinated aluminium (Grobet et al 1991).

\section{Conclusions}

VPI-5 was synthesized at lesser time duration i.e. at $2 \mathrm{~h}$, the earlier syntheses were minimum at $4 \mathrm{~h}$. XRD, SEM and FT-IR spectroscopic techniques show that the synthesized sample is well crystalline. Carbon and nitrogen analyses show that there is no template present in the VPI-5 as-synthesized sample. However, TG/DTA analy- sis reveals the presence of some adsorbed template molecules. ${ }^{27} \mathrm{Al}$ and ${ }^{31} \mathrm{P}$ MASNMR indicate the presence of three different types of aluminium and phosphorous. Two of them located at the connection of six and fourmembered rings with tetrahedrally coordinated to four framework oxygens and third in fused four membered ring at octahedrally coordinated to four framework oxygens and to two water molecules.

\section{Acknowledgement}

The author is thankful to CSIR, New Delhi, for a research associateship.

\section{References}

Barrer R M 1982 Hydrothermal chemistry of zeolites (London: Academic Press)

Breck D W 1973 Zeolite molecular sieves: Structure, chemistry, and use (London: Academic Press)

Davis M E, Saldarriage C, Montes C, Garces J and Crowder C 1988 Nature 331698

Davis M E, Montes C, Hathaway P E, Arhancet J P, Hasha D L and Garces J M 1989 J. Am. Chem. Soc. 1113919

Engelhardt G and Veeman W 1993 J. Chem. Soc., Chem. Commun. 623

Ernst R H, Eck V and Veeman W S 1993 J. Am. Chem. Soc. 1151168

Grobet P J, Martens J A, Balakrishnan I, Martens M and Jacobs P A 1989 Appl. Catal. 56 L21

Grobet P J, Samoson A, Gerts H, Martens J A and Jacobs P A 1991 J. Phys. Chem. 959620

He H and Klinowski J 1994 J. Phys. Chem. 981192

Lok B M, Messina C A, Patton R L, Gajek R T, Cannan T R and Flanigen E M 1984 J. Am. Chem. Soc. 1066092

McCusker L B and Baerlocher Ch 1991 Zeolites 11308

Parise J B 1985 J. Chem. Soc., Chem. Commun. 606

Robson H and Lillerud K P 2001 Verified synthesis of zeolitic materials (Amsterdam: Elsevier)

Rocha J, Kolodziejski W, He H and Klinowski J 1992 J. Am. Chem. Soc. 1144884

Rocha J, Esculas A P, Fernandez C and Amoureux J P 1996 J. Phys. Chem. 10017889

Schmidt W, Schuth F, Reichert H, Unger K and Zibrowius 1992 Zeolites 122

van Eck E R H and Veeman W S 1993 J. Am. Chem. Soc. 115 1168

Wilson S T, Lok B M, Messina C A, Cannon T R and Flanigen E M 1982 J. Am. Chem. Soc. 1041146

Yang G, Feng S and Xu R 1987 J. Chem. Soc., Chem. Commun. 1254 